\title{
The periareolar excision technique for improved scars in breast burns
}

\author{
Hong Sil Joo ${ }^{1}$, Seung Je Lee ${ }^{1}$, \\ Kun Yong Sung ${ }^{2}$ \\ ${ }^{1}$ Department of Plastic and \\ Reconstructive Surgery, Hanil General \\ Hospital, Seoul; ${ }^{2}$ Department of Plastic \\ and Reconstructive Surgery, Kangwon \\ National University Hospital, Kangwon \\ National University College of Medicine, \\ Chuncheon, Korea
}

\begin{abstract}
Regardless of size or severity, post-burn breast scars can be traumatic for patients. There are various approaches to post-burn scar management, but herein we present the results of a novel approach in which we tried to remove the scars in an early stage of treatment. Breast burn patients, whose wound area included the nipple-areolar complex, were treated using a periareolar incision design similar to that of periareolar reduction mammoplasty. The remnant scar was located only along the periareolar complex. As a result, more cosmetically satisfactory results were achieved compared to skin grafting or local flap procedures.
\end{abstract}

Keywords Burn / Breast / Post-burn scar

\section{INTRODUCTION}

Post-burn scars are a long-lasting issue for affected patients. Breast scarring is an esthetic concern for patients, even though the scars are not located on a frequently exposed body part. In particular, breast scars have a negative impact on women's self-esteem and body image. Therefore, it is important to try to leave as few traces of burn injuries as possible.

Treatment methods for breast burns usually include skin grafting or a local cutaneous flap. However, skin grafts have several disadvantages, including color mismatch, hypertrophic scarring, graft contracture, a patchwork appearance of the breast, and non-elastic skin texture.

Fig. 1 shows an example of an unfavorable scar. For this case, we chose a skin graft procedure for the left breast. At the 3-month follow-up, the scar showed a hard texture. The scarred skin displayed a rough and patch-like appearance and a different color.

Since scars develop after burn lesions, local cutaneous flaps have

Received: Feb 15, 2019 Revised: Mar 4, 2019 Accepted: Mar 4, 2019 Correspondence: Hong Sil Joo Department of Plastic and Reconstructive Surgery, Hanil General Hospital, 308 Uicheon-ro, Dobong-gu, Seoul 01450, Korea

Tel: +82-2-901-3114, Fax: +82-2-901-3214, E-mail: sil9113@gmail.com

Copyright @ 2019 The Korean Society for Aesthetic Plastic Surgery.

This is an Open Access article distributed under the terms of the Creative Commons Attribution Non-Commercial License (http://creativecommons.org/licenses/by-nc/4.0/) which permits unrestricted non-commercial use, distribution, and reproduction in any medium, provided the original work is properly cited. www.e-aaps.org disadvantages, such as leaving a visible hypertrophic scar and discoloration. In either case, the scars resulting from the local flap are undesirable.

To reduce scar visibility starting at the early stage of treatment, we used a periareolar incision method similar to that of periareolar reduction mammoplasty. We present cases of breast burns involving the nipple-areolar complex treated using our technique, which yielded better scar outcomes.

\section{CASE REPORTS}

All patients had at least second-degree burn injuries involving the nipple-areolar complex.

\section{Case 1}

A 53-year-old woman suffered burns of the right breast and abdomen caused by boiling water and steam. Seven days after the injury, the abdominal wound spontaneously healed with a conventional dressing. However, the breast wound showed a total loss of epidermis, dermal stain, and a thick eschar (Fig. 2). Therefore, 10 days after the burn injury, we planned a periareolar incision surgery with a technique similar to reduction mammoplasty.

We designed a circular incision pattern, in which the inner circle was drawn around the existing nipple-areolar complex with a $4-\mathrm{cm}$ diameter. The outer circle was located on the outside line of the wound. The distance from the areolar margin to the outer circle was $5.5 \mathrm{~cm}$. Full-layer excision was performed of the region including the burn wound, and the skin between the inner circle and the 


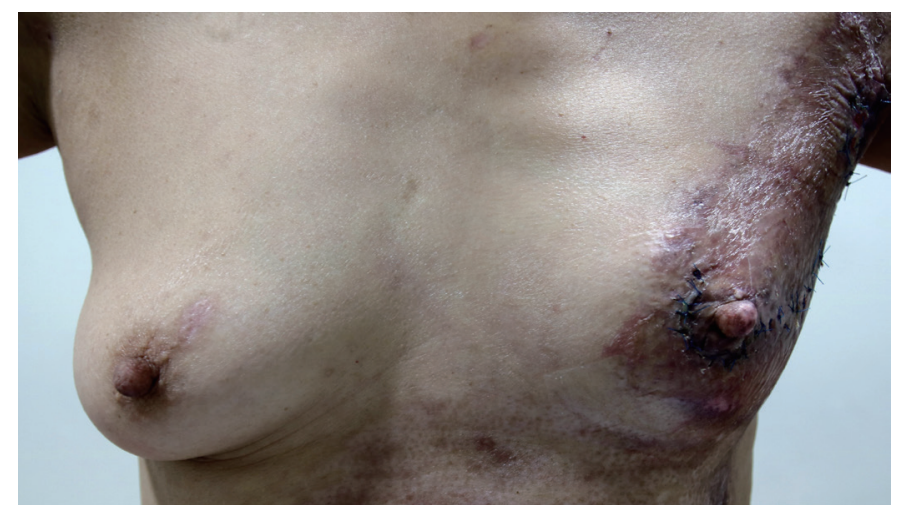

Fig. 1. A postoperative photograph after skin grafting. The photograph shows a hard-textured scar, different color, and patch-like appearance.

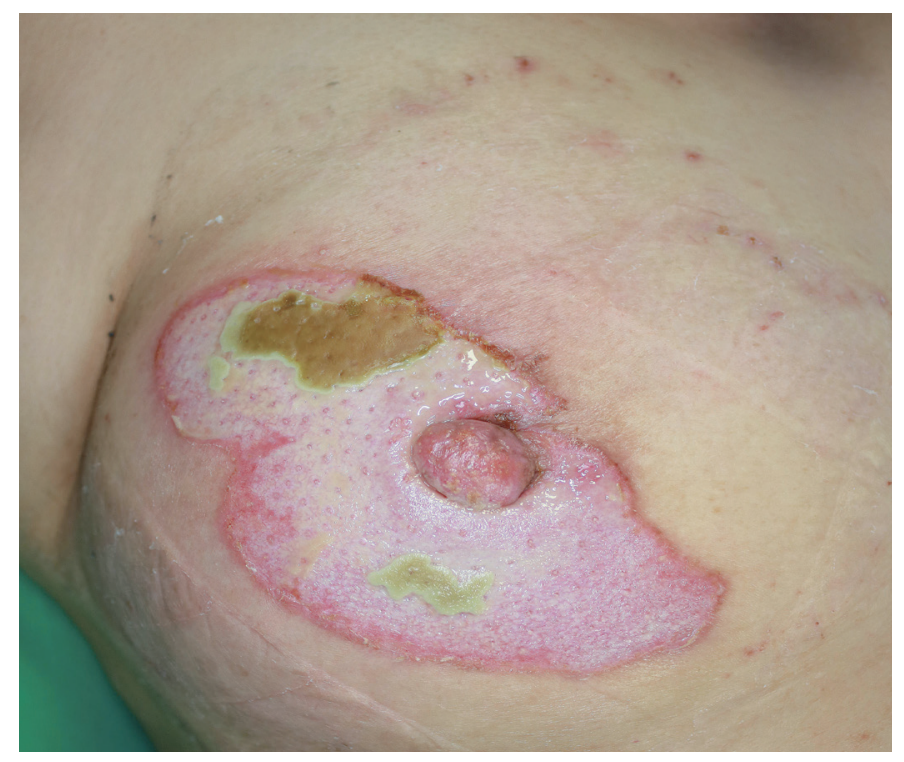

Fig. 2. A preoperative photograph. The photograph shows total loss of the epidermis, dermal stain, and a thick eschar.

outer circle was de-epithelialized (Fig. 3).

A purse-string suture was placed in the dermis of the outer skin flap and tied to create a defect approximately $4 \mathrm{~cm}$ long. To maintain long tension, non-absorbable suture material (3-0 polydioxanone [PDS]) was used to create the purse-string suture. The suture knot was placed in the deep subcutaneous tissue to prevent knot exposure. For enforcement, interrupted dermal and subcutaneous sutures were inserted with wrinkles at the outer skin flaps. The suture material was non-absorbable 4-0 PDS.

There was no need for additional surgery or signs of complications. At the 3-month follow-up, the final scar was contained to the periareolar area without marked spreading. Breast symmetry was satisfactory (Fig. 4).

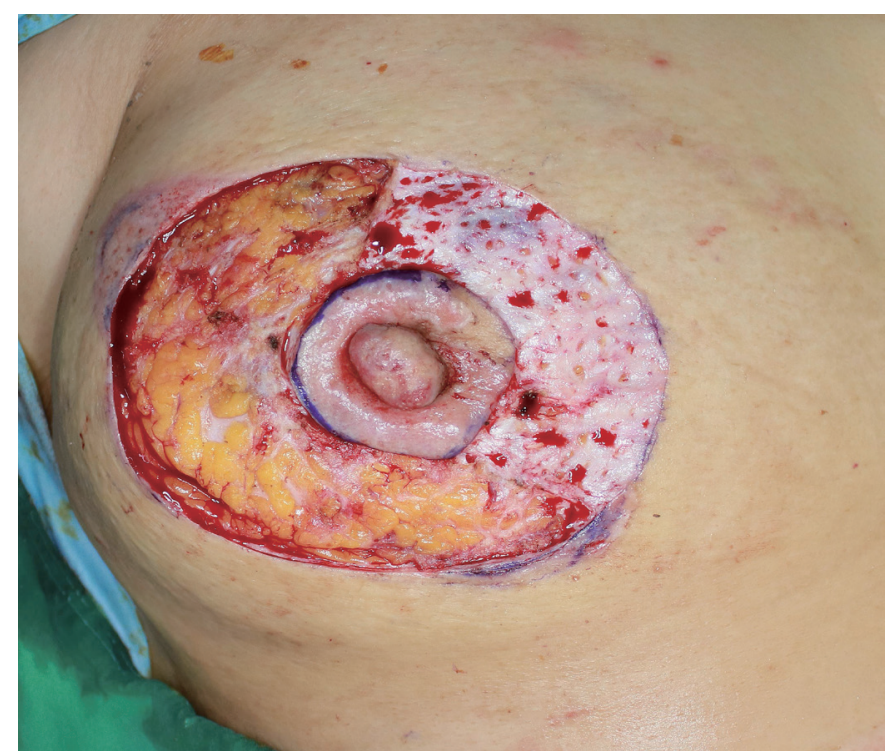

Fig. 3. An intraoperative photograph. Using a circular incision design, the burn wound underwent full-layer excision, and the skin between the inner circle and the outer circle was de-epithelialized.
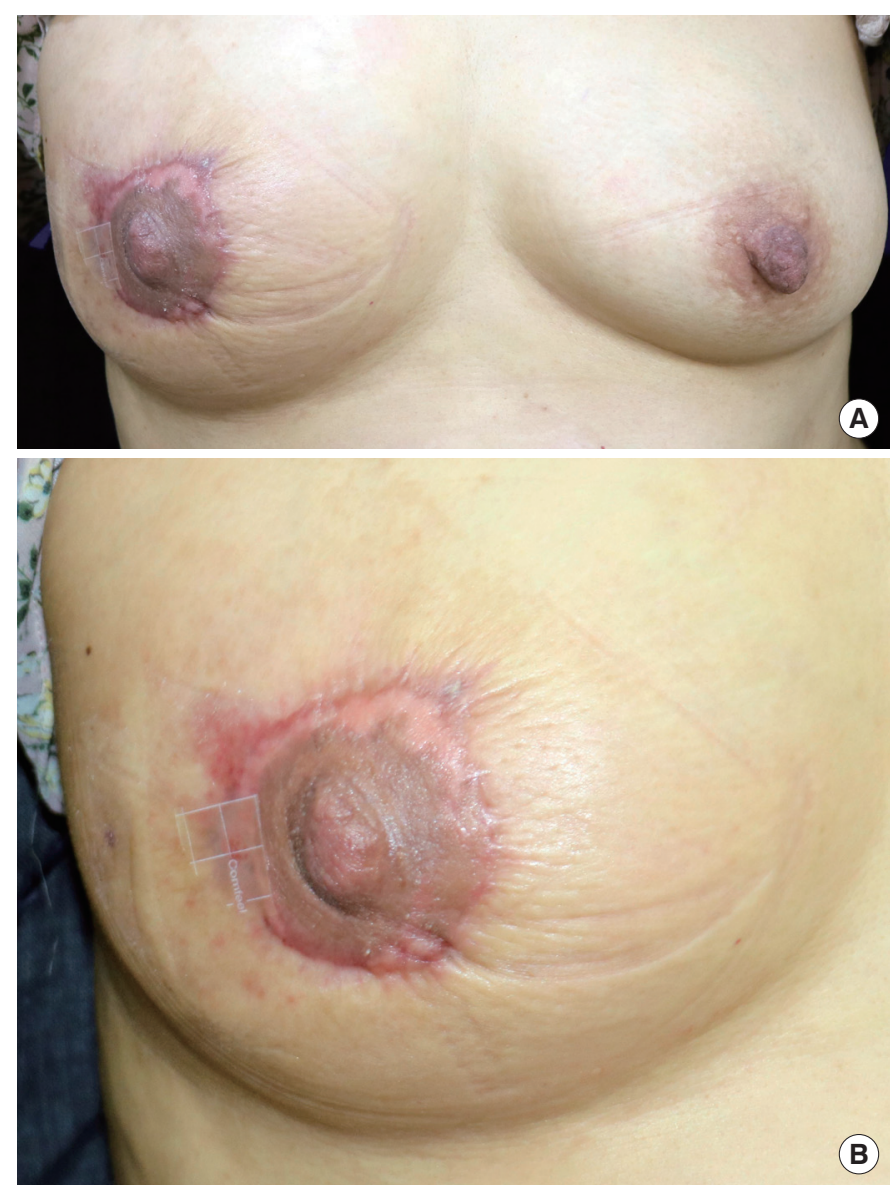

Fig. 4. Postoperative photographs. (A, B) This photograph, taken at a 3-month follow-up visit, shows good cosmesis. 


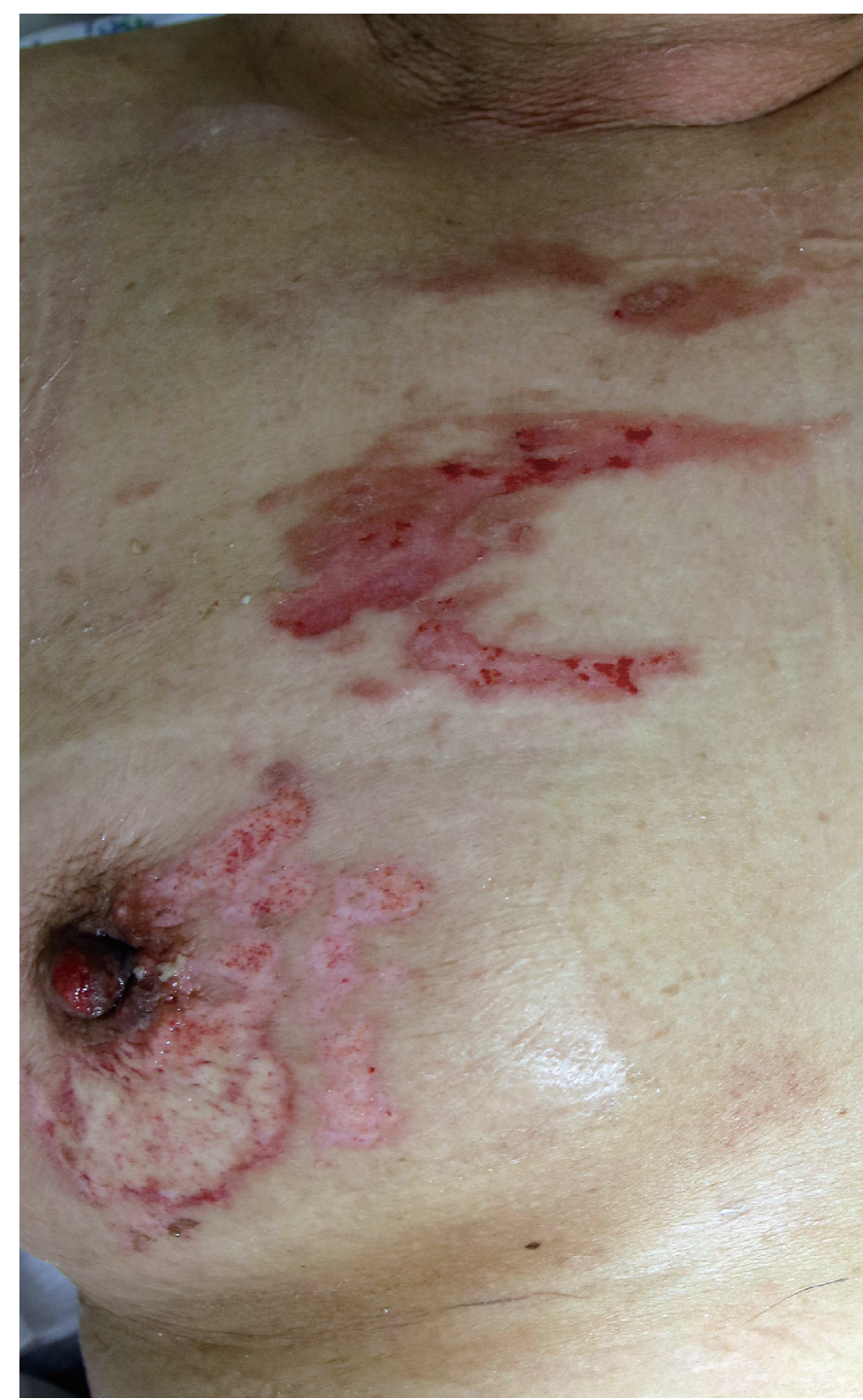

Fig. 5. A preoperative photograph. The wound shows the characteristics of a deep second-degree burn.

\section{Case 2}

A 65-year-old woman suffered burns of the face, chest, and abdomen caused by hot soup. The chest wounds, measuring $2.5 \times 8 \mathrm{~cm}$ and $6 \times 3.5 \mathrm{~cm}$, were located near the sternum and right periareolar area, respectively. Ten days after the injury, the breast wound was classified as a deep second-degree burn and showed a mottled wound condition and wet eschar; the other wounds were healed using conventional dressings (Fig. 5).

Surgery was performed at 12 days after injury in the same manner. The wounds showed adequate healing without complications. The wound condition at a 2-month follow-up was relatively good. A mild nipple projection discrepancy was present, but the final scars were relatively inconspicuous and breast symmetry was maintained (Fig. 6).
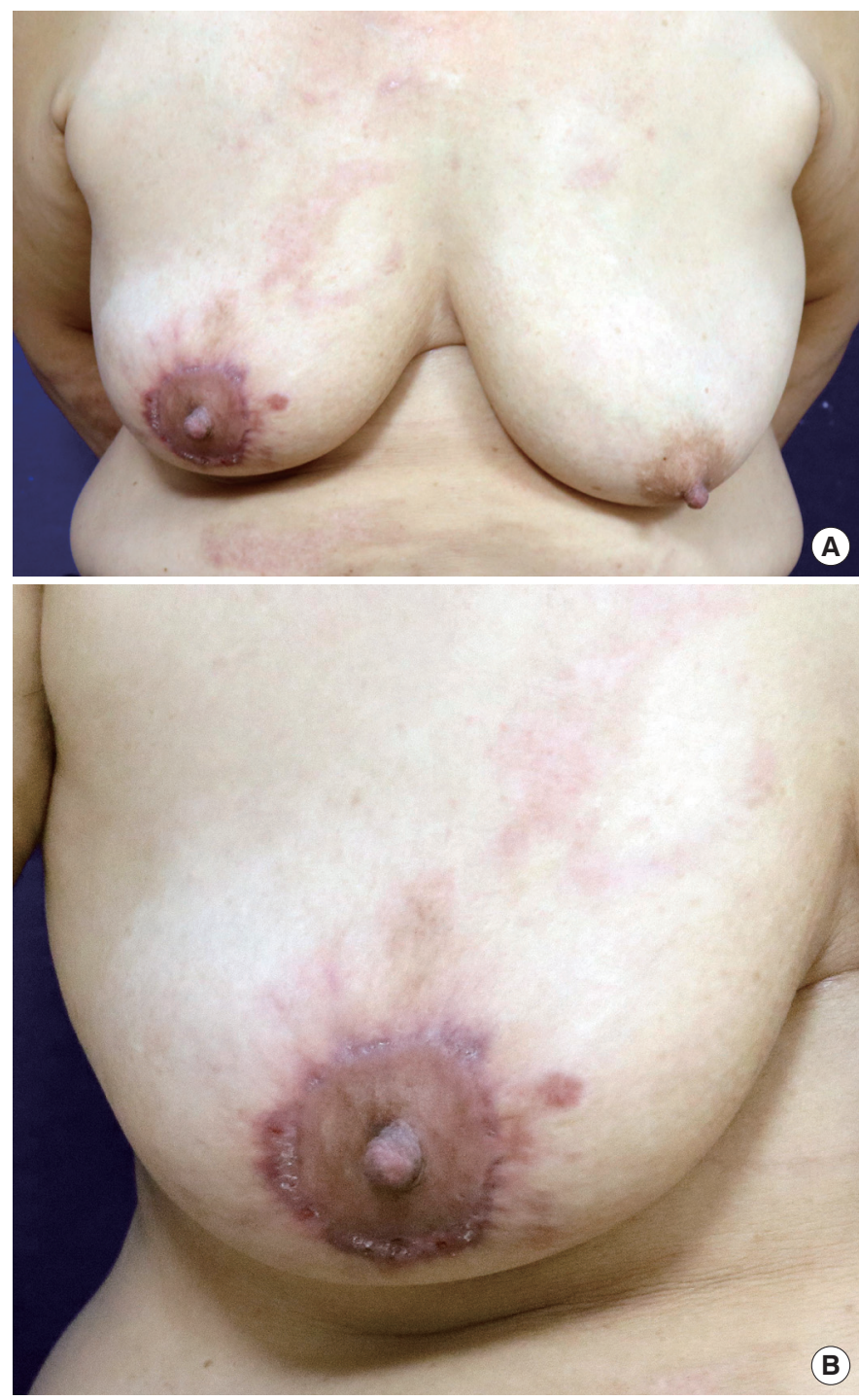

Fig. 6. Postoperative photographs. (A, B) This photograph, taken at a 2-month follow-up visit, shows a relatively inconspicuous scar.

\section{DISCUSSION}

The breasts are the most frequent site of burns within the trunk region [1]. It has been reported that $71 \%$ of female patients with burns to the anterior chest wall with involvement of the nipple-areolar complex require surgical intervention [2].

There are several methods to treat breast burns. The most common treatment is skin grafting $[3,4]$. Skin grafts can be used regardless of the burn wound size. In cases of narrow wounds, local cutaneous flaps can be used.

Scars resulting from skin grafts show a different color and texture compared to the light-colored, soft skin of the chest. The scar can also show a hypertrophic or contracted texture, lack of elasticity, and a patchwork appearance. Moreover, scars resulting from lo- 
cal cutaneous flaps remain present at the injury site and may show hypertrophic scarring, contraction, or discoloration.

Laser treatments, steroid injections, pressure garments, and other procedures can improve scar appearance. However, these treatments are time-consuming and costly, and even after years, the resultant skin will not be exactly the same as the natural chest skin. Therefore, we planned to make the scars less visible and to cover the wound using the chest skin starting at an early stage of treatment.

We performed a periareolar incision to camouflage the scar at the junction of the breast skin and pigmented areola. In addition, we applied a purse-string suture for the closure of wide periareolar defects.

The periareolar incision technique for reduction mammoplasty was first reported by Andrews et al. [5]. After the introduction of the periareolar incision technique, several variations were introduced by various authors [6]. One such variation involved applying a purse-string suture for the reduction and closure of wide periareolar skin defects [7]. Using purse-string sutures prevents areolar scar widening. Periareolar incision and purse-string sutures therefore produce less conspicuous scars.

In the cases where we performed our procedure, the burn wound was around the nipple-areolar complex, and the distance between the outer line and the inner line was about $5 \mathrm{~cm}$. However, that distance could be longer in patients with larger breasts.

Burn injuries that need surgical intervention may lead to severe scarring. More specifically, burn lesions on the breasts may not only lead to scarring, but also add to the psychological trauma related to the burn.

We reported two cases of satisfactory scar management in patients with breast burns. Treatment using a periareolar incision and purse-string suture might lead to improved scar cosmesis.

\section{NOTES}

\section{Conflict of interest}

No potential conflict of interest relevant to this article was reported.

\section{Ethical approval}

The study was performed in accordance with the principles of the Declaration of Helsinki.

\section{Patient consent}

The patients provided written informed consent for the publication and the use of their images.

\section{ORCID}

Hong Sil Joo

Seung Je Lee

Kun Yong Sung

https://orcid.org/0000-0001-6111-7163

https://orcid.org/0000-0002-2946-009X

https://orcid.org/0000-0002-3114-0001

\section{REFERENCES}

1. Burns BF, McCauley RL, Murphy FL, et al. Reconstructive management of patients with greater than 80 percent TBSA burns. Burns 1993;19: 429-33.

2. McCauley RL, Beraja V, Rutan RL, et al. Longitudinal assessment of breast development in adolescent female patients with burns involving the nipple-areolar complex. Plast Reconstr Surg 1989;83:676-80.

3. Rubin LR. The burned female breast. N Y State J Med 1975;75:865-9.

4. Neale HW, Smith GL, Gregory RO, et al. Breast reconstruction in the burned adolescent female (an 11-year, 157 patient experience). Plast Reconstr Surg 1982;70:718-24.

5. Andrews JM, Yshizuki MM, Martins DM, et al. An areolar approach to reduction mammaplasty. Br J Plast Surg 1975;28:166-70.

6. Lista F, Austin RE, Ahman J. Reduction mammaplasty with short scar techniques. In. Nahabedian M, Neligan PC, editors. Plastic surgery. 4th ed. London: Mosby Elsevier; 2018. p. 160-73.

7. Peled IJ, Zagher U, Wexler MR. Purse-string suture for reduction and closure of skin defects. Ann Plast Surg 1985;14:465-9. 